\title{
Imported visceral leishmaniasis and immunosuppression in seven Norwegian patients
}

\author{
Thomas Schwartz ${ }^{1,2^{*}}$, Mogens Jensenius ${ }^{1}$, Bjørn Blomberg ${ }^{3,4}$, Cathrine Fladeby ${ }^{5}$, Arild Mæland ${ }^{1}$ and
} Frank O. Pettersen ${ }^{1,6}$

\begin{abstract}
Background: Visceral leishmaniasis $(\mathrm{VL})$ is a protozoal disease that may be aggravated by immunosuppression. In recent years, a growing number of patients with chronic diseases use biological treatment. When such immunosuppressed patients travel to endemic areas, they are facing the risk of VL. Increased incidence of leishmaniasis is reported in endemic areas like the Mediterranean basin, an area frequently visited by Norwegian tourists. This may lead to an increased number of patients, many presenting to health personnel unfamiliar with the disease, in their home countries.
\end{abstract}

Methods: We reviewed the files of seven immunosuppressed patients with $\mathrm{VL}$, admitted to Oslo and Haukeland University Hospitals in Norway in the period 2009-2018.

Results: The patients were 41-83 (median 66) years of age; four had rheumatic disease all of whom used methotrexate; one had advanced HIV infection, one had inflammatory bowel disease and one had myelofibrosis. Leishmania infantum was confirmed in five patients by polymerase chain reaction (PCR) and sequencing. In the remaining two patients, a definite Leishmania species could not be identified. All patients had a history of recent recreational travel to Spain. Most patients underwent extensive diagnostic work-up before diagnosed with VL. All received treatment with liposomal amphotericin B and all were cured; albeit two after re-treatment due to relapse.

Conclusions: Visceral leishmaniasis is a potentially life-threatening but usually treatable condition. It is endemic in Southern Europe, including popular tourist destinations such as the Mediterranean basin. It is relatively unknown to most medical practitioners in non-endemic areas and clinical vigilance is required to identify those who are infected.

Keywords: Leishmaniasis, Travel medicine, Rheumatic disease, Autoimmune disease, Immunosuppression, Tumor necrosis factor alpha inhibitor, Methotrexate

\section{Background}

Leishmaniasis is a chronic protozoal disease, caused by parasites of the genus Leishmania and is transmitted by sandflies, which are active at dusk and night and even indoor. Visceral leishmaniasis (VL) is the most severe form with 95\% mortality untreated [1]. It is caused either by Leishmania donovani which is transmitted between humans, or by Leishmania infantum which is a zoonosis

\footnotetext{
* Correspondence: thomasschwartz1410@gmail.com

${ }^{1}$ Department of Infectious Diseases, Ullevål, Oslo University Hospital, Oslo, Norway

${ }^{2}$ Department of Medical Microbiology, Vestre Viken, Drammen, Norway Full list of author information is available at the end of the article
}

and known as L.chagasi in the New World. The disease can present years after transmission [1]. VL has caused devastating epidemics during famine and wartime, particularly on the Horn of Africa [2]. Ninety percent of the cases occur on the Indian subcontinent, the Horn of Africa (L. donovani) and in Brazil (L. infantum) $[1,3]$. $\mathrm{VL}$ is also endemic to Southern Europe, including popular tourist destinations lining the Mediterranean basin, however to a smaller extent. In the period 2006-2014, the reported average number of VL cases per year in Spain and France were 206 and 14, respectively (WHO, Global Health Observatory). In this region, the responsible parasite is L. infantum and dogs act as the primary

(C) The Author(s). 2019 Open Access This article is distributed under the terms of the Creative Commons Attribution 4.0 International License (http://creativecommons.org/licenses/by/4.0/), which permits unrestricted use, distribution, and 
zoonotic reservoir [4]. The incidence of VL appears to increase in Southern Europe [5]. Acre, et al., recently documented the largest leishmaniasis outbreak in Europe in modern times, occurring outside of Madrid in the years 2009-2012 with 446 reported cases [6]. HIV-induced immunosuppression increases the risk of developing VL once infected $[7,8]$. Among 160 patients with VL in the Madrid outbreak, 16 had HIV infection and 34 were immunosuppressed due to other causes. In recent years, the use of biological treatment for various chronic diseases has increased dramatically, improving many people's lives. Thus, they take part in the modern international mass tourism, including areas endemic to VL. The number of susceptible patients facing the risk of VL has therefore increased. Here, we present seven immunosuppressed patients diagnosed with imported VL in Norway.

\section{Methods}

From 2009 to 2018, our referral hospitals diagnosed seven immunosuppressed patients with VL after returning from travel to Spain. Five patients were diagnosed and had treatment initiated at Oslo University Hospital (OUS) and one (patient 6) at Haukeland University Hospital (HUH) in Bergen. Patient 2 fell sick in Thailand where he was diagnosed and treated before he was transferred to OUS for treatment completion. All patients gave their oral and written consent to the use of their data in this report. Our article is a retrospective descriptive case series without interventions. Approval from Regional Ethics Committee for Medical Research was therefore not relevant. Publication has been done in accordance with OUS and HUH's policy of personal and private security.

The VL diagnosis was based on a combination of histopathological, serological, polymerase chain reaction (PCR) and sequencing analysis. Pathologists at our university clinics performed histological analysis (Fig. 1). Leishmania serology tests were analyzed at the Public Health Agency of Sweden, Stockholm, Sweden. The serological test can identify Leishmania-infection but cannot distinguish between species. Since 2015, Department of Microbiology, OUS, has offered an in-house real-time PCR using18S rRNA gene as target for Leishmania detection and Leishmania hsp70 gene sequencing for Leishmania species identification [9].

\section{Results}

Table 1 shows the epidemiological characteristics of the seven patients (median age 66 years, range $41-83$ years). Six patients $(85,7 \%)$ were males, four $(57,1 \%)$ had rheumatic disease, one had advanced HIV infection, one inflammatory bowel disease (ulcerative colitis) and one myelofibrosis. All patients presented with the triad of fever, pancytopenia and splenomegaly. Comprehensive diagnostic procedures such as computer tomography, bone marrow examination, microbiological tests and culturing were performed in all

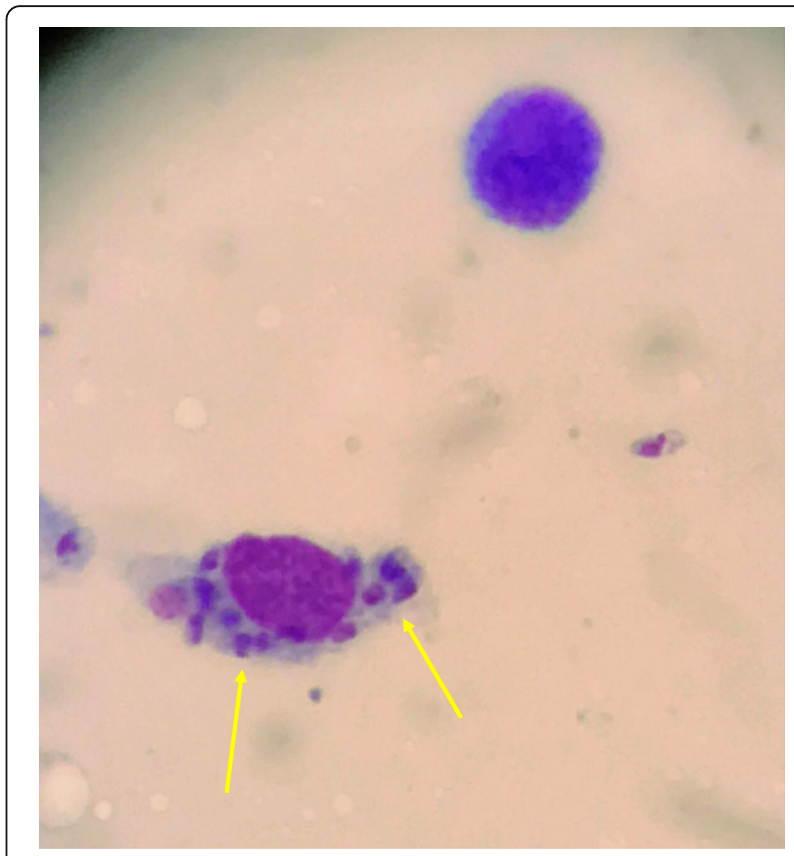

Fig. 1 Amastigotes (yellow arrows) in bone marrow aspirate, with May-Grünwald-Giemsa staining from patient 5 , magnified $\times 40$

patients due to the severity of the clinical presentations. Patient 5 was immunosuppressed due to an unrecognised HIV infection with a CD4 cell count of 19 cells $/ \mathrm{mm}^{3}$ at presentation. All, except patient 5, acquired infection during recreational travels.

Investigations, treatment and outcome of the patients are listed in Table 2. In five of seven patients $(71,4 \%$, patient 1, 4, 5, 6 and 7), PCR and sequencing were performed on bone marrow, spleen aspirate, spleen biopsy and/or peripheral blood and L. infantum infection was confirmed. In one case only, the initial diagnosis was made by PCR (patient 7). In five cases $(71,4 \%)$, the initial leishmaniasis diagnosis was based on direct microscopic detection of amastigotes within macrophages in aspirate (Fig. 1), either from skin (patient 1), spleen (patient 2 and 6) or bone marrow (patient 3 and 5), before serology or PCR was performed.

Patient 2 and 3 were diagnosed by serology and histology before PCR was available to us. They had both travelled to destinations endemic to other species than $L$. infantum (Table 2), and to the Mediterranean area; therefore a definite Leishmania species could not identified.

All four patients with rheumatic disease used methotrexate $(57,2 \%$ of all patients), either with prednisolone $(42,9 \%)$, with adalimumab $(14,3 \%)$ or alone $(14,3 \%)$. All patients received treatment with liposomal amphotericin B (L-AmB) in total doses $1400 \mathrm{mg}-2350 \mathrm{mg}(20-37 \mathrm{mg} / \mathrm{kg})$ iv, and all were cured. When diagnosed with B-cell lymphoma 16 months' post-treatment, patient 3 relapsed with VL without any possible re-exposure to VL. Treatment 


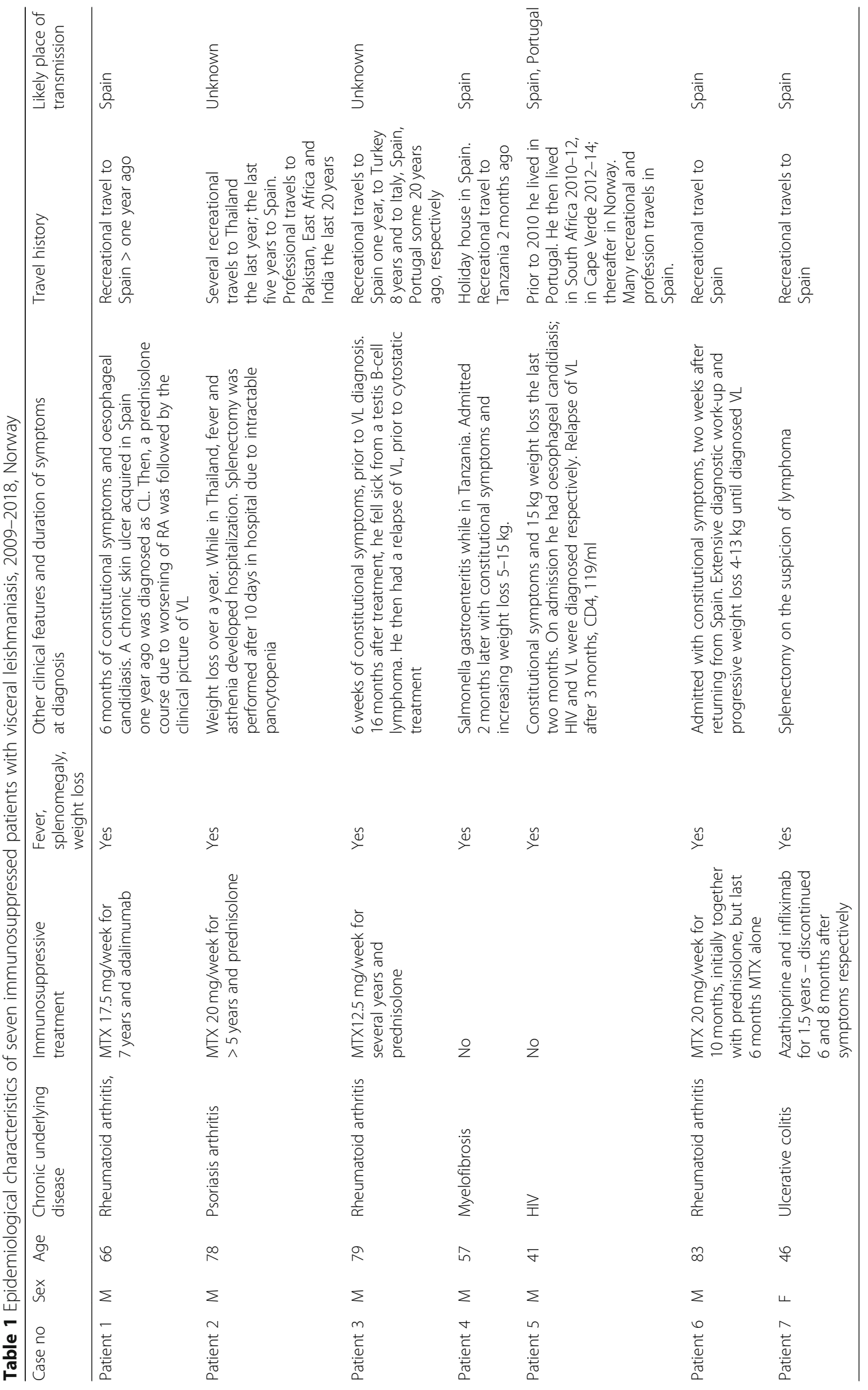




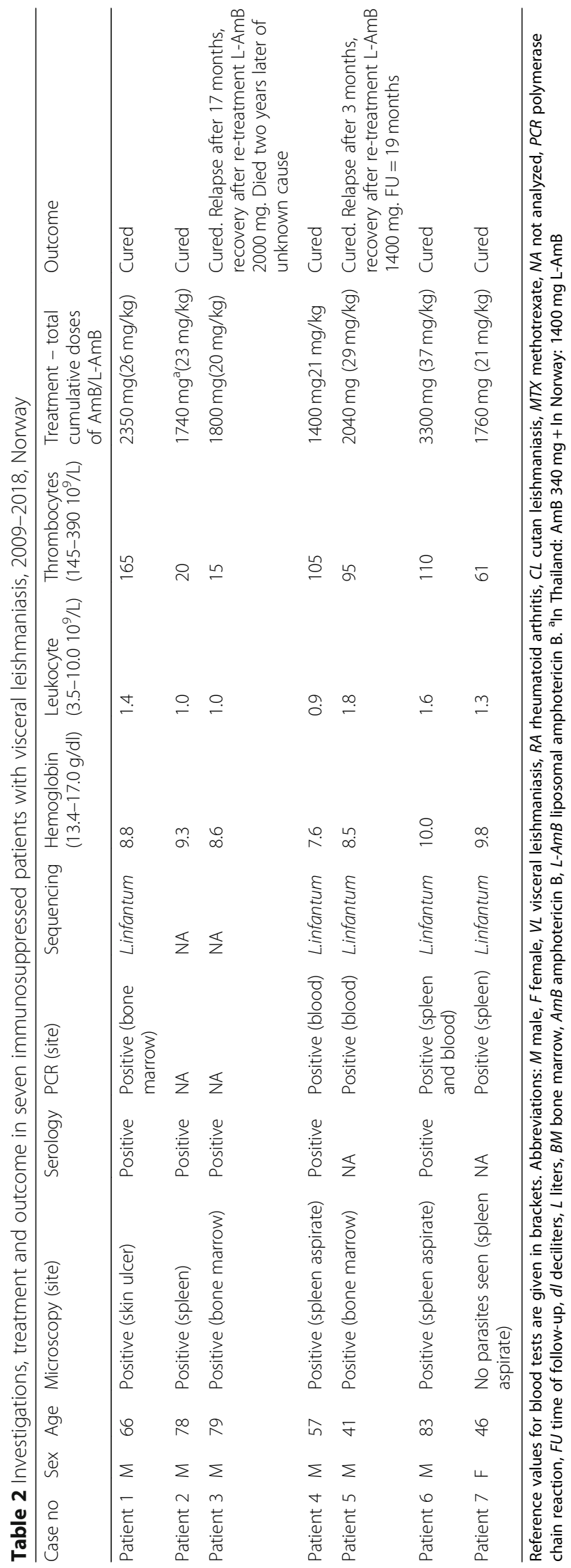


outcome was not assessed by Leishmania-PCR in blood, as this was not available in Norway at that time. Patient 5 relapsed three months after initial treatment; he had not received secondary prophylaxis with L-AmB and was still severely immunosuppressed by HIV. 12 months after retreatment, there was no sign of VL. Patient 3 and patient 5 initially received total doses of 1800 and $2040 \mathrm{mg}$ with L$\mathrm{AmB}$, respectively.

\section{Discussion}

During the last decades, the growing population of immunocompromised patients has taken part in modern tourism. They visit areas endemic to leishmaniasis such as southern parts of Europe where they may be exposed to VL. Physicians in non-endemic areas of Northern Europe may not be familiar with VL, the potential risk of infection, or the presence of VL in popular tourist destinations along the Mediterranean. Therefore, we expect an increase in VL-cases in areas non-endemic to Leishmania because of the travel activity of immunosuppressed patients to VL endemic areas [6]. Furthermore, the incidence of leishmaniasis cases is increasing in popular tourist destinations such as Spain. Lastly, more cases of VL may be detected due to an improvement of available diagnostic tools such as PCR and sequencing, given that medical doctors in non-endemic areas are alert and primed for the possibility of VL [10-12].

VL has been associated with immunosuppressive disorders like HIV infection, myeloproliferative disorders and cancers, but also with immunosuppressive therapy for autoimmune diseases and after solid-organ transplantation $[13,14]$. It is possible that autoimmune diseases per se represent a risk factor for developing VL. But to our knowledge, no systematic studies have addressed the risk of VL in patients with rheumatic or other autoimmune diseases not on treatment with immunosuppressive drugs. In our material, all patients with rheumatic disease (four) received immunosuppressive therapy. VL has been demonstrated in case reports of rheumatic patients treated with tumor necrosis factor alpha (TNF- $\alpha$ ) antagonists [15-17] or methotrexate [18-20] and in three nonrheumatic patients on corticosteroids [21]. Patient 7 with ulcerative colitis developed VL while on TNF- $\alpha$ antagonist treatment. In literature, we have only found one single case of VL in a patient with inflammatory bowel disease (Crohn's disease) on TNF- $\alpha$ antagonists [22].

TNF- $\alpha$ monoclonal antibodies have become a cornerstone in modern treatment of many chronic inflammatory disorders and have received an increased attention as a risk factor for $\mathrm{VL}$ than other immunosuppressive drugs $[17,23]$. TNF- $\alpha$ has pro-inflammatory effects but also plays an important role in the defense against intracellular infections, such as leishmaniasis. Inhibition or lack of TNF- $\alpha$ activity seem to induce an increased risk of leishmaniasis as demonstrated in mouse models [24].

The risk of VL if treated with methotrexate is only scarcely documented [18-20]. The patients with rheumatic diseases in our report were all treated with methotrexate. Methotrexate has been used in treatment of rheumatoid arthritis (RA) since the 1960's and is often combined with other drugs. Notably, in a literature search, Chen, et al., described eight patients with RA developing VL while treated with the combination of adalimumab and methotrexate [23]. Methotrexate is a competitive inhibitor of folic aciddependent enzymes, leading to impaired purine and pyrimidine synthesis which inhibits proliferation of lymphocytes [25]. As the cellular immune system is important against intracellular infections, it is plausible that this renders patients on methotrexate at risk of VL.

Corticosteroids are also widely used in the treatment of autoimmune diseases and, like methotrexate, are often used in combination with other drugs. We have not identified any publications on VL in rheumatic patients on prednisolone alone, although several of the reported cases on anti- TNF- $\alpha$ and methotrexate therapy had received corticosteroids as well $[18,23]$. In a large controlled study on 25,139 solid organ transplanted patients in Spain and Brazil, 36 cases of VL was identified [26]. A multivariate logistic regression analysis was performed, and the use of corticosteroids - not mycophenolate, cyclosporine or tacrolimus - was the only risk factor associated with VL. It has also been shown that prolonged use of corticosteroids in Leishmania-infected mice, led to decreasing levels of TNF- $\alpha$ and other cytokines, along with increasing numbers of amastigotes in the spleen [27].

$\mathrm{L}-\mathrm{AmB}$ is the treatment of choice against infections caused by Leishmania infantum [28]. Recent guidelines recommend an increased dose of L-AmB in immunocompromised patients: $4 \mathrm{mg} / \mathrm{kg} /$ day iv on days $1-5,10$, 17, 24, 31 and 38 (total dose of $40 \mathrm{mg} / \mathrm{kg}$ ) [28]. Secondary prophylaxis is only recommended to HIV infected individuals as long as CD4 T lymphocytes counts are < 200 cells $/ \mathrm{mm}^{3}$. Assessment of Leishmania PCR to avoid post-treatment relapse is recommended for at least one-year post-treatment [28]. Our patients received total doses of L-AmB in the range of $20-37 \mathrm{mg} / \mathrm{kg}$ (Table), i.e. lower than current guidelines. Patient 2 was diagnosed with VL and had treatment initiated in Thailand with non-liposomal amphotericin, before completing therapy in Norway with L-AmB. As we observed two relapses among seven patients after receiving standard doses of L$\mathrm{AmB}$, it appears reasonable from our limited experience to provide immunocompromised patients with a higher cumulative dose of $\mathrm{L}-\mathrm{AmB}$.

Four of the patients had traveled to various destinations endemic to VL, such as Eastern and Western Mediterranean Basin, East Africa, Pakistan and Thailand. 
It is possible that some of these patients got infected with leishmaniasis years ago, remained asymptomatic, and presented with VL once given immunosuppressive therapy. However, Spain seems like the most probable place of transmission, due to the timing, lengths and/or frequencies of stay in this region, with a possible exception of patient 2 whose place of transmission remains unknown.

All our seven patients underwent a rather extensive diagnostic work-up before a final diagnosis was made. Malignancies and haematological diseases were invariably high on the list of the differential diagnoses. PCR was performed only to confirm the diagnosis after positive microscopy, serology or histology, and for species identification in most cases. This could reflect that PCR as a readily available test modality for leishmaniasis is yet to become known to Norwegian medical doctors. Our laboratory at OUS now offers PCR and sequencing (the only in Norway, population 5.25 million people). As a result of this, the awareness of leishmaniasis seems to have increased. During the last three years a total of 32 cases were diagnosed, among whom eight had VL (including one of the present patients) [29].

\section{Conclusion}

We present seven immunosuppressed Norwegian patients suffering from life-threatening VL most likely acquired around the Mediterranean basin. A growing number of people susceptible to VL travel to Leishmania-endemic destinations. Medical practitioners, particularly those who care for immunocompromised patients of any cause, need to be aware of the risk of VL and question their patients of their travels including the recreational trip to Spain.

\section{Abbreviations}

AmB: Amphotericin B; HUH: Haukeland University Hospital; OUS: Oslo University Hospital; PCR: Polymerase chain reaction; RA: Rheumatoid arthritis; TNF-a: Tumor necrosis factor alpha; VL: Visceral Leishmaniasis

\section{Acknowledgements}

We are grateful to the patients, giving us the opportunity to describe and publish their case histories.

\section{Authors' contributions}

The article was drafted by T.S. and F.O.P. and all authors critically reviewed the manuscript. All authors approved the final version of the manuscript. All authors take responsibility for the integrity and accuracy of the case information collected and presented. Study conception and design: M.J., A.M., F.O.P and T.S. Acquisition of data: M.J., A.M., F.O.P, B.B. and T.S. Laboratory analyses: C.F. and F.O.P.

\section{Funding}

None

\section{Availability of data and materials}

Not applicable

\section{Ethics approval and consent to participate}

Approval from Regional Ethics Committee for Medical Research was not relevant for this non-intervention, descriptive case series. Publication has been done in accordance with OUS and HUH's policy of personal and private security.

\section{Consent for publication}

All patients (in one case legal guardian since the patient died) gave their oral and written consent to the use of their data in this report.

\section{Competing interests}

The authors declare that they have no competing interests.

\section{Author details}

${ }^{1}$ Department of Infectious Diseases, Ullevål, Oslo University Hospital, Oslo, Norway. ${ }^{2}$ Department of Medical Microbiology, Vestre Viken, Drammen, Norway. ${ }^{3}$ Norwegian National Advisory Unit on Tropical Infectious Diseases. Department of Medicine, Haukeland University Hospital, Bergen, Norway. ${ }^{4}$ Department of Clinical Science, University of Bergen, Bergen, Norway.

${ }^{5}$ Department of Microbiology, Ullevål, Oslo University Hospital, Oslo, Norway. ${ }^{6}$ Regional Advisory Unit of Imported and Tropical Diseases, Oslo University Hospital, Oslo, Norway.

Received: 11 May 2019 Accepted: 9 August 2019

Published online: 22 August 2019

\section{References}

1. Ma S. Leishmaniasis. Manson's tropical diseases. 23rd ed; 2014. p. 631-51.

2. Seaman J, Mercer AJ, Sondorp E. The epidemic of visceral leishmaniasis in western upper Nile, southern Sudan: course and impact from 1984 to 1994. Int J Epidemiol. 1996:25(4):862-71.

3. Bern C, Maguire JH, Alvar J. Complexities of assessing the disease burden attributable to leishmaniasis. PLoS Negl Trop Dis. 2008;2(10):e313.

4. Martin-Sanchez J, Morales-Yuste M, Acedo-Sanchez C, Baron S, Diaz V, Morillas-Marquez F. Canine leishmaniasis in southeastern Spain. Emerg Infect Dis. 2009;15(5):795-8.

5. Ready PD. Leishmaniasis emergence in Europe. Euro Surveill. 2010;15(10):19505.

6. Arce A, Estirado A, Ordobas M, Sevilla S, Garcia N, Moratilla L, et al. Reemergence of leishmaniasis in Spain: community outbreak in Madrid, Spain, 2009 to 2012. Euro Surveill. 2013;18(30):20546.

7. Diro E, Lynen L, Ritmeijer K, Boelaert M, Hailu A, van Griensven J. Visceral Leishmaniasis and HIV coinfection in East Africa. PLoS Negl Trop Dis. 2014; 8(6):e2869.

8. van Griensven J, Carrillo E, Lopez-Velez R, Lynen L, Moreno J. Leishmaniasis in immunosuppressed individuals. Clin Microbiol Infect. 2014;20(4):286-99.

9. Van der Auwera G, Maes I, De Doncker S, Ravel C, Cnops L, Van Esbroeck M, et al. Heat-shock protein 70 gene sequencing for Leishmania species typing in European tropical infectious disease clinics. Euro Surveill. 2013:18(30):20543.

10. Buonomano R, Brinkmann F, Leupin N, Boscacci R, Zimmermann A, Muller $\mathrm{N}$, et al. Holiday souvenirs from the Mediterranean: three instructive cases of visceral leishmaniasis. Scand J Infect Dis. 2009;41(10):777-81.

11. Ehehalt U, Schunk M, Jensenius M, van Genderen PJ, Gkrania-Klotsas E, Chappuis $F$, et al. Leishmaniasis acquired by travellers to endemic regions in Europe: a EuroTravNet multi-Centre study. Travel Med Infect Dis. 2014;12(2): 167-72.

12. Weitzel T, Muhlberger $N$, Jelinek T, Schunk M, Ehrhardt S, Bogdan C, et al. Imported leishmaniasis in Germany 2001-2004: data of the SIMPID surveillance network. Eur J Clin Microbiol Infect Dis. 2005;24(7):471-6.

13. Bogdan C. Leishmaniasis in rheumatology, haematology and oncology: epidemiological, immunological and clinical aspects and caveats. Ann Rheum Dis. 2012:71(Suppl 2):i60-6.

14. Antinori S, Cascio A, Parravicini C, Bianchi R, Corbellino M. Leishmaniasis among organ transplant recipients. Lancet Infect Dis. 2008;8(3):191-9.

15. Neumayr AL, Morizot G, Visser LG, Lockwood DN, Beck BR, Schneider S, et al. Clinical aspects and management of cutaneous leishmaniasis in rheumatoid patients treated with TNF-alpha antagonists. Travel Med Infect Dis. 2013;11(6):412-20.

16. Berry CE, Tsai J, Tierney A, Pickles R. Visceral leishmaniasis in a patient taking adalimumab for rheumatoid arthritis. Med J Aust. 2013;198(6):331-3.

17. Zanger P, Kotter I, Kremsner PG, Gabrysch S. Tumor necrosis factor alpha antagonist drugs and leishmaniasis in Europe. Clin Microbiol Infect. 2012; 18(7):670-6.

18. Trigkidis K, Geladari E, Kokkinakis E, Vallianou N. Visceral Leishmaniasis in a patient with rheumatoid arthritis undergoing treatment with methotrexate: case report and review of the literature. Eur J Rheumatol. 2017;4(2):139-41. 
19. Hadjipetrou A, Anyfantakis D, Gkogkou A, Palla K, Lagoudaki E, Milonaki T, et al. Visceral leishmaniasis in a psoriatic arthritis patient treated with methotrexate. Infez Med. 2014;22(3):230-5.

20. Loarce-Martos J, Garrote-Corral S, Gioia F, Bachiller-Corral J. Visceral leishmaniasis in a patient with rheumatoid arthritis treated with methotrexate. Reumatol Clin. 2017. [Epub ahead of print]. https://doi.org/1 0.1016/.j.reuma.2017.07.024.

21. Pittalis S, Nicastri E, Spinazzola F, Ghirga P, De Marco M, Paglia MG, et al. Leishmania infantum leishmaniasis in corticosteroid--treated patients. BMC Infect Dis. 2006;6:177.

22. Hernandez M, Gonzalez-Lama Y, Ramos A, Martinez-Ruiz R, Calvo M, Matallana $V$, et al. Visceral leishmaniasis as an unusual infectious complication in a patient with Crohn's disease treated with infliximab. Gastroenterol Hepatol. 2015;38(6):411-2.

23. Tung Chen Y, Perales C, Lacruz J, Senent L, Salavert M. Visceral leishmaniasis infection during adalimumab therapy: a case report and literature review. Int J Rheum Dis. 2014;17(7):822-4.

24. Korner H, McMorran B, Schluter D, Fromm P. The role of TNF in parasitic diseases: still more questions than answers. Int J Parasitol. 2010;40(8):879-88.

25. Meier FM, Frerix M, Hermann W, Muller-Ladner U. Current immunotherapy in rheumatoid arthritis. Immunotherapy. 2013;5(9):955-74.

26. Clemente W, Vidal E, Girao E, Ramos AS, Govedic F, Merino E, et al. Risk factors, clinical features and outcomes of visceral leishmaniasis in solidorgan transplant recipients: a retrospective multicenter case-control study. Clin Microbiol Infect. 2015;21(1):89-95.

27. Rousseau D, Suffia I, Ferrua B, Philip P, Le Fichoux Y, Kubar 」L. Prolonged administration of dexamethasone induces limited reactivation of visceral leishmaniasis in chronically infected BALB/c mice. Eur Cytokine Netw. 1998;9(4):655-61.

28. Aronson N, Herwaldt BL, Libman M, Pearson R, Lopez-Velez R, Weina P, et al. Diagnosis and treatment of Leishmaniasis: clinical practice guidelines by the Infectious Diseases Society of America (IDSA) and the American Society of Tropical Medicine and Hygiene (ASTMH). Clin Infect Dis. 2016;63(12):e202-e64.

29. $H B, O P F, C F$. The use of $P C R$ and sequencing to diagnose leishmaniasis a two year experience from Oslo University hospital. Madrid: ECCMID; 2018.

\section{Publisher's Note}

Springer Nature remains neutral with regard to jurisdictional claims in published maps and institutional affiliations.

Ready to submit your research? Choose BMC and benefit from:

- fast, convenient online submission

- thorough peer review by experienced researchers in your field

- rapid publication on acceptance

- support for research data, including large and complex data types

- gold Open Access which fosters wider collaboration and increased citations

- maximum visibility for your research: over $100 \mathrm{M}$ website views per year

At $\mathrm{BMC}$, research is always in progress.

Learn more biomedcentral.com/submissions 